A N N A L E S Annales de Bretagne et des Pays de l'Ouest

\title{
Bernard Merdrignac, Le sport au Moyen Âge
}

\section{Daniel Pichot}

\section{OpenEdition}

\section{Journals}

Édition électronique

URL : http://journals.openedition.org/abpo/1398

DOI : $10.4000 / a b p o .1398$

ISBN : 978-2-7535-1491-1

ISSN : 2108-6443

\section{Éditeur}

Presses universitaires de Rennes

Édition imprimée

Date de publication : 20 octobre 2003

Pagination : 137-138

ISBN : 978-2-86847-929-7

ISSN : 0399-0826

\section{Référence électronique}

Daniel Pichot, «Bernard Merdrignac, Le sport au Moyen Âge », Annales de Bretagne et des Pays de l'Ouest [En ligne], 110-3 | 2003, mis en ligne le 20 décembre 2005, consulté le 22 septembre 2020. URL http://journals.openedition.org/abpo/1398 ; DOI : https://doi.org/10.4000/abpo.1398 
comme l'affirmait Colgan. Enfin, le manuscrit D IV 18 de la Biblioteca Nazionale de Turin comporte dans les marges inférieures de ses premiers folii des extraits d'une version d'origine irlandaise d'un Martyrologe versifié (connu par ailleurs par un manuscrit rémois du $\mathrm{IX}^{\mathrm{e}}$ siècle, publié au XVII ${ }^{\mathrm{e}}$ siècle par Luc d'Achery et disparu depuis). Ce dernier aurait été compilé soit pour l'Église d'York, soit pour celle de Ripon et Michel Lapidge estime qu'il pourrait remonter à la seconde moitié du VIII ${ }^{\text {e }}$ siècle. Quant à la version irlandaise (en hexamètres dactyliques irréguliers comme sa source originelle), sous réserve d'études ultérieures, celleci a pu être réalisée durant une large fourchette chronologique, du $\mathrm{VIII}^{\mathrm{e}}$ siècle au $\mathrm{XII}^{\mathrm{e}}$ siècle, et elle provient probablement de Clonmacnoise. En tout cas, sa présence dans le manuscrit de Turin atteste qu'elle était en usage dans l'Église irlandaise à la fin du XII ${ }^{\mathrm{e}}$ siècle.

L'érudition déployée dans cet ouvrage par le professeur Pádraig Ó Riain procure au lecteur une incontestable satisfaction intellectuelle. Toutefois ce plaisir n'est pas gratuit. En replaçant ces productions liturgiques dans leur contexte historique, cette publication impeccable des derniers Martyrologes irlandais demeurés inédits (ou du moins devenus difficiles d'accès) permet de mieux appréhender l'action des chanoines augustiniens qui tissaient leur réseau de prieurés à un tournant de l'histoire de l'Église irlandaise, au moment de l'intervention dans l'île des Plantagenêts et de leurs vassaux.

Bernard MERDRIGNAC

Merdrignac, Bernard, Le sport au Moyen Âge, Rennes, Presses universitaires de Rennes, 2002, 340 p., $13 €$.

Sous un titre relativement provoquant, Bernard Merdrignac nous offre dans un livre très dense moins une histoire du sport au Moyen Âge qu'une réflexion sur ce que pouvait être la relation des sociétés médiévales avec l'activité physique et le corps, le jeu et le loisir. La mise en perspective de toute une série d'activités bien médiévales comme les tournois, des rapprochements parfois surprenants mais révélateurs offrent beaucoup plus qu'un manuel commode, ce que peut-être aussi cet ouvrage, fruit d'un enseignement auprès d'étudiants "sportifs ". Écrit d'un style alerte et non sans un humour, relayé par un caricaturiste débutant, cet essai propose aussi une foule de renseignements précis et divers qui couvrent nombre d'activités physiques dans un espace géographique des plus vastes où apparaît fréquemment l'Irlande chère à l'auteur et passablement méconnue. Des compléments bibliographiques, un glossaire, des notices biographiques et surtout un abondant dossier de soixante-dix pages de documents souvent très originaux complètent fort bien l'ouvrage.

Le premier chapitre invite à une réflexion nécessaire. Le sport moderne est né au XIX ${ }^{\mathrm{e}}$ siècle dans le cadre d'une société bien spécifique mais ne peut-on pas parler, d'une certaine manière, de sport dans les périodes antérieures? L'auteur fait alors appel aux théoriciens qui ont proposé les lectures les plus diverses, voire les plus opposées. Le sport est-il inhérent à la nature humaine et, dans ce cas, il n'aurait guère d'histoire, se cantonne t-il dans une naissance contemporaine, est-il le fruit d'une évolution d'une "sportivisation " du jeu, le fruit d'un "processus de civilisation " comme le propose Norbert Hélias? Pour aborder le sujet et rechercher les aspects sportifs dans nombre d'activités médiévales, B. Merdrignac s'appuie largement sur la théorie exposée par R. Caillois dans Les 
jeux et les hommes, faisant du jeu une activité " séparée, incertaine, improductive, réglée et fictive ». Si le Moyen Âge a ignoré le sport, il a connu un concept particulier qui semble y préluder en partie sous le nom de déport qui s'applique au divertissement qui peut se faire dans le cadre de compétitions désignées par le mot ébattement.

Ces bases posées, il est indispensable d'examiner la position des médiévaux à l'égard du corps. Ici, B. Merdrignac fait justice de nombreux clichés en montrant que le Moyen Âge n'a pas eu systématiquement le mépris du corps qu'on lui prête souvent et que la position demeura beaucoup plus nuancée, la règle de saint Benoît se montre particulièrement équilibrée à cet égard. L'étude de l'éducation physique au Moyen Âge le montre bien. Les jeux sportifs sont multiples, de la lutte au lancer de pierre, et l'étude des récréations enfantines dévoile d'autres exemples. Une place particulière est consacrée à la formation physique du chevalier. L'étude des enfances de Duguesclin et de Boucicault est très révélatrice mais, si cela prend pour nous bien des aspects sportifs, l'inspiration générale est tout autre.

Les chapitres suivants sont consacrés à l'analyse d'activités qui présentent un grand nombre de caractères sportifs et entretiennent des liens apparents avec des sports modernes. La chasse à courre ou au faucon apparaît très vite comme un loisir fortement aristocratique, un véritable marqueur social et l'auteur rappelle avec à propos que le véritable sportsman anglais fut d'abord l'aristocrate qui se livrait à la chasse au renard. Joutes et tournois, et les jeux guerriers en général, présentent beaucoup d'aspects sportifs : spécialité aristocratique, engagement physique, compétition et spectacle.

Les jeux de balle faillirent devenir un vrai sport et la paume n'est pas étrangère au tennis moderne. $B$. Merdrignac tente de démêler l'écheveau complexe des continuités qui n'en sont pas, des ruptures et des implications sociales. D'abord apanage des clercs, le jeu de balle se popularisa et gagna de larges couches de la population. Par bien des traits, le sport véritable se dessine : le terrain propre dérivé du cloître où jouaient les clercs, l'élaboration de règles etc. Mais l'association dans les esprits de la paume à la France ancienne ruina son crédit. Pareillement, la soule, pratique populaire violente, peut présenter des analogies avec foot-ball et rugby mais elle s'inscrit profondément dans l'identité villageoise et demeura un jeu peu réglementé.

Tout en restant très ouvert, le livre propose une mise en perspective des activités physiques en les reliant profondément aux pratiques sociales du Moyen Âge et provoque une réflexion nourrie qui lance des perspectives éventuellement inattendues sur des réalités classiques du Moyen Âge. Si l'on ajoute l'intérêt du gros dossier documentaire qui nous offre des textes souvent rares, l'ensemble se présente comme un livre riche et stimulant, dommage que des coquilles un peu abondantes le déparent quelque peu.

Daniel PICHOT

Pichot, Daniel, Le village éclaté. Habitat et société dans les campagnes de l'Ouest au Moyen Âge, PUR, 2002, 395 p.

L'ouvrage de Daniel Pichot, fruit de son habilitation, est d'abord et avant tout une réflexion sur la définition et, ce faisant, la naissance du village dans cette France de l'Ouest (Anjou, Maine et Bretagne) profondément marquée par 